\title{
Photodynamic diagnosis of ovarian cancer using hexaminolaevulinate: a preclinical study
}

\author{
F Lüdicke ${ }^{*, 1}$, T Gabrecht ${ }^{2}$, N Lange ${ }^{2}$, G Wagnières ${ }^{2}, \mathrm{H}$ van den Bergh ${ }^{2}$, L Berclaz' and AL Major ${ }^{1,3}$ \\ 'Fondation pour Recherches Médicales, University of Geneva, 64 Avenue de la Roseraie, 1211 Geneva, Switzerland; ${ }^{2}$ Institute of Environmental \\ Engineering, Swiss Federal Institute of Technology (EPFL) Lausanne, Switzerland; ${ }^{3}$ Department of Obstetrics and Gynaecology, University Hospital \\ Geneva, Switzerland
}

The unfailing detection of micrometastases during surgery of patients suffering from ovarian cancer is mandatory for the optimal management of this disease. Thus, the present study aimed at determining the feasibility of detecting micrometastases in an ovarian cancer model using the intraperitoneal administration of the photosensitiser precursor hexaminolaevulinate (HAL). For this purpose, HAL was applied intraperitoneally at different concentrations (4-12 mM) to immunocompetent Fischer 344 rats bearing a syngeneic epithelial ovarian carcinoma. The tumours were visualised laparoscopically using both white and blue light (D-light, Karl Storz, Tuttlingen, Germany), and the number of peritoneal micrometastases detected through HAL-induced photodiagnosis (PD) was compared to standard white light visualisation. Fluorescence spectra were recorded with an optical fibre-based spectrofluorometer and the fluorescence intensities were compared to the protoporphyrin IX (PpIX) fluorescence induced by 5-aminolevulinic acid under similar conditions. The number of metastases detected by the PD blue light mode was higher than when using standard white light abdominal inspection for all applied concentrations. Twice as many cancer lesions were detected by fluorescence than by white light inspection. The hexyl-ester derivative produced higher PpIX fluorescence than its parent substance aminolevulinic acid at the same concentration and application time. Fluorescence contrast between healthy and cancerous tissue was excellent for both compounds. To overcome poor diagnostic efficiency and to detect peritoneal ovarian carcinoma foci in the large surface area of the human peritoneal cavity, HAL fluorescence-based visualisation techniques may acquire importance in future and lead to a more correct staging of early ovarian cancer.

British Journal of Cancer (2003) 88, 1780-1784. doi:I0.1038/sj.bjc.6600958 www.bjcancer.com

(c) 2003 Cancer Research UK

Keywords: photodynamic diagnosis; ovarian cancer

Only ovarian cancer patients who have undergone a thorough surgical staging procedure, with early-stage and well or moderately differentiated tumours, may be considered as cured by surgery alone, and therefore do not require adjuvant therapy (Trimbos et al, 1991). Occult extra-ovarian metastases are found in about $15-20 \%$ of patients initially diagnosed as early ovarian cancer confined to the ovary. The confirmed absence of such micrometatstatic lesions in the peritoneal cavity does have impact on the decision-making process of the physician with respect to the treatment regimen as well as on patient's quality of life.

Statistically, these occult lesions are found in the diaphragm (7\%), the omentum (5\%), peritoneal biopsy specimens (10\%), and peritoneal cytology (20\%) (Leblanc et al, 2000).

The magnitude of the problem becomes even more apparent following optimally performed re-staging operations. Up to $30 \%$ of patients with presumed early-stage ovarian cancer will be upstaged if re-explored, and approximately two-thirds of these patients will have stage III disease (Bagley Jr et al, 1973; Piver, 1982; Young et al, 1983; Helewa et al, 1986; Buchsbaum et al, 1989; Soper et al, 1992). Despite attempts at improving staging through computed tomo-

*Correspondence: F Lüdicke; E-mail: Frank.Ludicke@dim.hcuge.ch Received I October 2002; revised 6 March 2003; accepted 6 March 2003 graphy (CT), magnetic resonance imaging (MRI), and other established imaging diagnostic tools, the detection of residual micrometastatic disease remains a challenge to the gynaecological oncologist and collaborating disciplines.

To overcome poor diagnostic efficiency in the large surface area of the human peritoneal cavity, fluorescence-based visualisation techniques might acquire greater importance in the future.

Fluorescence photodetection (PD) takes advantage of the optical properties of the tissues, either inherent (autofluorescence) or induced by exogenously administered photoactive compounds. The fact that cancerous tissue often shows differences not only in its biological behaviour, but also in the resulting optical characteristics has allowed PD of malignant disease in fields such as urology, (Jichlinski et al, 1997a,b; Kriegmair et al, 1999) dermatology (Orenstein et al, 1997) and pulmology (Monnier Ph et al, 1990).

Although not a photoactive compound itself, exogenously administered 5-aminolaevulinic acid (ALA), the first committed intermediate in the haeme biosynthetic pathway, results in a temporary accumulation of fluorescing porphyrin precursors, particularly protoporphyrin IX (PpIX). Administration of exogenous ALA bypasses the negative feedback control and induces the preferential accumulation of PpIX in malignant cells of epithelial origin (for a review, see Peng et al, 1997) The fluorescence of PpIX can easily be used for diagnostic purposes when excited by light 
with in the blue range of the visible spectrum (Wagnieres et al, 1998). In many medical areas, ALA-induced PD has replaced the photosensitiser compounds used previously, because of its simple application scheme (systemic or topical), almost complete absence of side effects, short-lasting phototoxicity, and good discrimination between malignant and nonmalignant tissue (Peng et al, 1997).

We were previously able to show in a preclinical and clinical setting that ALA-induced PD can successfully make visible ovarian cancer micrometastases in the peritoneal cavity (Major et al, 1997, 2002a, b; Hornung et al, 1998). While ALA-induced PD has proven its feasibility in detecting ovarian cancer micrometastases, the pharmacological properties of ALA make it suboptimal when applied topically or, as in our research, intraperitoneally in ovarian cancer patients. 5-Aminolaevulinic acid is a hydrophilic molecule, and its penetration across biological membranes is partially compromised. 5-Aminolaevulinic acid-induced PpIX formation after topical application shows considerable heterogeneity and the depth of penetration is limited (Lange et al, 1999, 2001). More lipophilic derivatives of ALA are currently under clinical assessment, in attempts to enhance ALA's poor bioavailability. It has been shown that the hexyl-ester derivative of ALA (hexaminolaevulinate (HLA)) represents a good compromise between aqueous solubility and lipophilicity.

Our aim was to determine the feasibility of detecting micrometastases in an ovarian cancer model using the intraperitoneal administration of the photosensitiser precursor HAL. Additionally, we aimed to quantify the peritoneal micrometastases through HAL-induced PD, and to compare the number of detected lesions with the one obtained through standard white light visualisation.

\section{MATERIALS AND METHODS}

Female Fischer (F-344) rats $(120-160 \mathrm{~g})$ were housed in a pathogen-free animal facility at the 'Fondation pour la recherche médicale', Geneva. They were given unlimited access to commercial basal diet and water. The experimental protocol for the use of animals for these studies was approved by the Institutional Ethics Review Board and the local veterinary office. The study was carried out according to the UKCCCR guidelines for the welfare of animals in experimental neoplasia (Workman et al, 1998). In particular, it should be noted that the experimental system was set up so as to detect ovarian cancer metastases at a very early stage of the disease when implants are not or only difficult to visualise with the naked eye. In our system, this was the case after 5 weeks of tumour induction.

The NuTu-19 cell line is a poorly differentiated Fischer 344 ratderived epithelial ovarian cancer cell line (Rose et al, 1996). Cells were cultured in DMEM medium (Gibco Life Technologies, Carlsbad, USA) enriched with $10 \%$ foetal calf serum (Gibco Life Technologies), penicillin $25 \mathrm{IE} \mathrm{ml}^{-1}$, streptomycin $25 \mathrm{mg} \mathrm{ml}^{-1}$, and incubated under standardised conditions $\left(37^{\circ} \mathrm{C}, 7 \%\right.$ carbon dioxide, $100 \%$ humidity). One million cells per animal were harvested with $0.25 \%$ trypsin (Gibco Life Technologies), washed with phosphate-buffered saline (PBS) (Gibco Life Technologies) and injected intraperitoneally.

At 5 weeks after tumour induction, crystallised ALA hydrochloride (Merck, Darmstadt, Germany) was diluted in PBS and titrated with $\mathrm{NaOH}$ to $\mathrm{pH}$ 7.4. The synthesis of HAL is described elsewhere (Kloek et al, 1998; Lange et al, 1999). In all, $2 \mathrm{ml}$ of solution (4-12 mM HAL in PBS titrated with $\mathrm{HCl}$ to $\mathrm{pH} 7.4,8 \mathrm{~mm}$ ALA) was injected intraperitoneally into each rat.

For PD, the D-Light system (Storz ${ }^{\mathrm{TM}}$ ) was used. A $300 \mathrm{~W}$ xenon short-arc lamp emitted blue light in the range from 375 to $440 \mathrm{~nm}$. A foot pedal made it possible to switch between blue-violet fluorescence excitation light and white light. In the endoscopic eyepiece, a yellow long-pass filter reduces the reflected blue light, intensifying the contrast between the red fluorescent and nonfluorescent areas of the healthy surrounding tissue. Tumours and premalignant lesions fluoresces bright red in the violet excitation light.

Point spectroscopy is a highly sensitive method for measuring fluorescence signals, making it a useful tool for in vivo pharmacokinetic measurements. In this study, fluorescence emission spectra were recorded with an optical fibre-based spectrofluorometer based on a Peltier-cooled CCD coupled to a spectrograph (Cromex 250, SI Instruments, Germany). Excitation light $\left(\lambda_{\mathrm{ex}}=405 \mathrm{~nm}\right)$ from a $75 \mathrm{~W}$ high-pressure xenon lamp (UXL$75 \mathrm{XE}$, Ushio Inc., Japan) was spectrally resolved by a quarter metre monochromator (Chromex 250, SI Instruments, Germany) with a bandwidth of $5 \mathrm{~nm}$ and an excitation filter, SCHOTT BG3 (Schott AG, Mainz, Germany), mounted on a filter wheel. A stepper motor (SMC 100, Princeton Instruments Inc., USA) controlled this excitation filter wheel, which was equipped with different low-pass filters to purify the excitation light. Excitation energy measured at the distal end of the fibre tip was determined with a calibrated power-metre (Optical Power Meter 840, Newport, USA). A filter setup allows the acquisition of fluorescence emission spectra between 455 and $900 \mathrm{~nm}$. The setup and data acquisition were controlled by a 486 personal computer using CSMA software (SI Instruments $\mathrm{GmbH}$, Germany). An aqueous solution of rhodamine $\mathrm{B}\left(c=1 \times 10^{-6} \mathrm{moll}^{-1}\right)$ in a $10 \mathrm{~mm}$ quartz cuvette was used as a reference. Emission spectra of the reference were recorded before and after each measurement. All measurements were normalised to the peak value of the reference to give comparable results corrected for day-to-day fluctuations in the excitation light energy or detection pathway alignment. Point fluorescence measurements of cancerous and normal tissue were performed with a $500 \mu \mathrm{m}$ fibre probe. Each point measurement was repeated three times. The peritoneal autofluorescence spectrum of a rat without any medication was used as reference spectrum, and all data of the spectrofluorometer presented in this work are the measured fluorescence values after subtraction of the autofluorescence.

A total of 11 photosensitised rats were killed $2 \mathrm{~h}$ after instillation of ALA or HAL. A midline incision from the xyphoid process to the symphysis pubis was made and the viscera were explored. To avoid bleaching of the photosensitiser, all procedures were carried out under dimmed room light.

The number of lesions in each photosensitised animal was counted independently by two investigators, one performing examination under white light and the other using fluorescence diagnosis. Several biopsies were taken from fluorescent sites.

\section{RESULTS}

Metastases were most frequently found on the caudal side of the diaphragm, the peritoneum, and less frequently on the omentum and intestine. All biopsies taken from lesions seen by normal inspection or detected through PD were histopathologically proven cancer.

The number of metastases detected by the PD blue light mode was significantly higher $\left(\chi^{2}\right.$ test, $\left.P<0.01\right)$ than when using standard white light abdominal inspection for all applied concentrations (Table 1). About twice as many cancer lesions were detected by PpIX fluorescence than by white light inspection. Figure 1 shows a sequence of white light and blue light images of small cancerous metastases through PD $2 \mathrm{~h}$ following injection of HAL $(8 \mathrm{~mm})$, which would have been missed by standard white light diagnosis.

A typical fluorescence spectrum registered by point spectrofluorometric measurement of a metastasis is shown in Figure 2. It depicts the characteristic fluorescence emission spectrum of PpIX and was the same independently on the used concentration or precursor. 
Table I Numbers of metastases detected by white light and blue light detection using HAL (4-12 mM) and ALA (8 mM)

\begin{tabular}{lccrrr}
\hline $\begin{array}{l}\text { Concentration (mM) } \\
\text { (number of animals) }\end{array}$ & Precursor & $\begin{array}{c}\text { Time after } \\
\text { injection (h) }\end{array}$ & $\begin{array}{l}\text { White } \\
\text { light }\end{array}$ & $\begin{array}{c}\text { Blue } \\
\text { light }\end{array}$ & Ratio \\
\hline $4(3)$ & $\mathrm{HAL}$ & 2.5 & 9 & 23 & 2.6 \\
$8(4)$ & $\mathrm{HAL}$ & 2.0 & 70 & 123 & 1.8 \\
$\mathrm{I} 2(2)$ & $\mathrm{HAL}$ & 2.0 & 3 & 8 & 2.7 \\
$8(2)$ & $\mathrm{ALA}$ & 2.0 & 10 & 16 & 1.6 \\
\hline
\end{tabular}
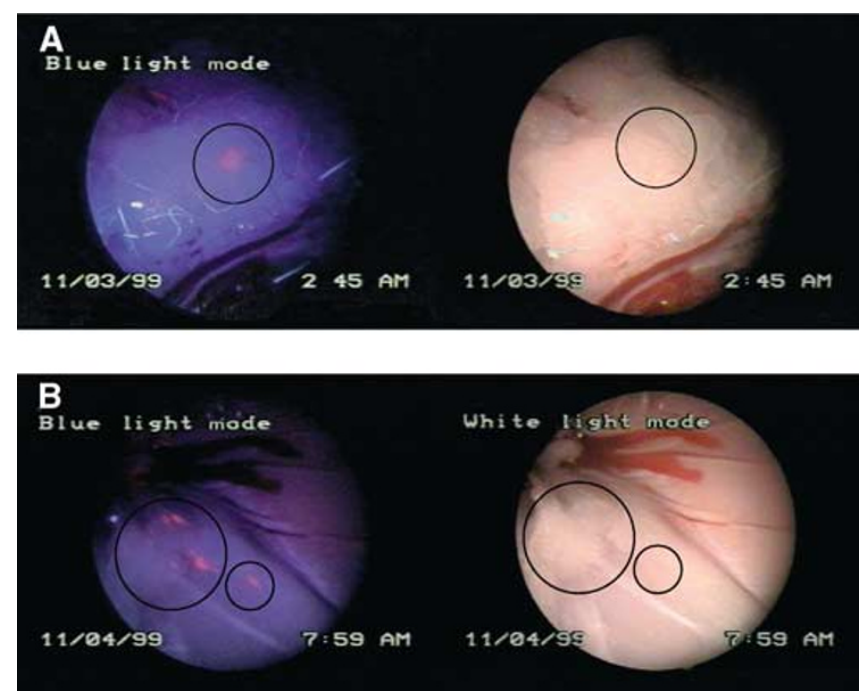

Figure I Peritoneal metastases in blue and white light mode. Image $(\mathbf{A})$ shows a lesion that is only visible in the blue light mode, but not by white light (position marked by a circle) ( $8 \mathrm{mM} \mathrm{HAL}$ after $2 \mathrm{~h}$ ). Image (B) shows three lesions visible by both blue and white light (big circle) and one only detectable by fluorescence (small circle) (8 mM HAL after $2 \mathrm{~h}$ ).

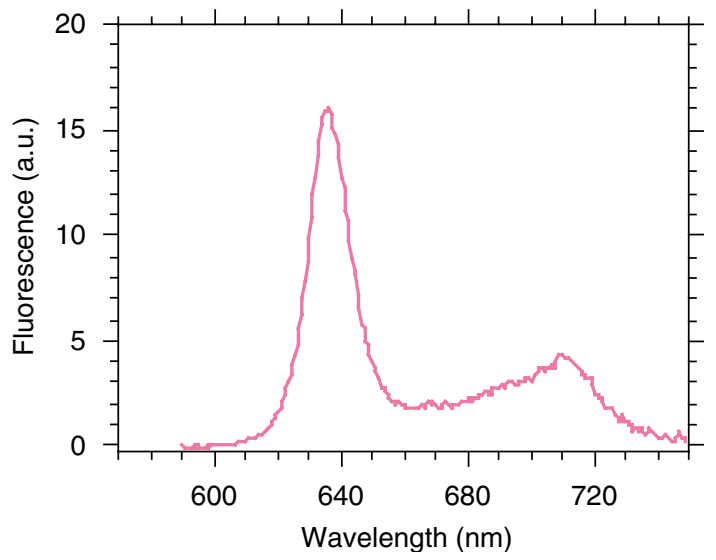

Figure 2 Typical PplX fluorescence spectrum of peritoneal ovarian cancer metastasis $2 \mathrm{~h}$ after i.p. administration of $8 \mathrm{mM} \mathrm{HAL}$.

In total, we measured 44 tumour sites and 44 normal tissue sites in 11 rats. The mean values for each condition for tumour and normal tissue are shown in Figure 3. Tumour to normal tissue ratios for the fluorescence intensities ranged from 2.7 (4 mM HAL) to 10 for $\mathrm{HAL}$ at $8 \mathrm{~mm}$. The mean fluorescence intensities were significantly different (Mann-Whitney $U$-test, $P<0.01$ ) between



Figure 3 Mean fluorescence emission of healthy peritoneal (empty box) and cancerous (grey box) tissue. Four different sites for normal tissue and four sites of cancerous tissue were measured in each rat. In all, $8 \mathrm{mM}$ ALA and 4- $12 \mathrm{mM} \mathrm{HAL}$ were applied and fluorescence was measured $2 \mathrm{~h}$ after injection (number of measurements/number of animals; bar $=$ s.d.).

normal and cancerous tissue for ALA and HAL. Increasing the dosage of HAL from 8 to $12 \mathrm{~mm}$ did not further increase the fluorescence harvest.

At $8 \mathrm{~mm}$ concentration, the hexyl-ester derivative produced significantly higher PpIX fluorescence as compared to ALA (Figure 3); however, visually the fluorescence contrast between healthy and cancerous tissue was excellent for both the compounds.

\section{DISCUSSION}

Owing to its good tumour selectivity and excellent clinical tolerance, the photoactive precursor ALA is increasingly used as photosensitiser in photodynamic therapy and fluorescence photodetection. 5-Aminolaevulinic acid can be applied topically (creams, instillation) or systemically (oral, inhalation) (Peng et al, 1997). 5Aminolaevulinic acid-induced PpIX appears to be cleared from the body within $24 \mathrm{~h}$ of induction, whether the route is systemic or topical (Webber et al, 1997). Systemic administration of doses $>30 \mathrm{mg} \mathrm{kg}^{-1}$ resulted in a decrease of systolic blood pressure with a median of $80 \mathrm{mmHg} 6-7 \mathrm{~h}$ later. Lower doses did not affect the haemodynamic variables (Heyerdahl et al, 1997; Webber et al, 1997). To date, no side effects have been reported following topical application of ALA. Similarly, installation of up to $16 \mathrm{~mm}$ HAL into the bladder did not result in any side effects (Lange et al, 1999).

Gahlen et al $(2001,2002)$ have shown that local, intraperitoneal photosensitisation with ALA is a more reliable and effective method than systemic photosensitisation with ALA for detection of small or occult peritoneal tumours. More lipophilic derivatives of ALA, such as HAL, that have better bioavailability than ALA should therefore show good performance in the detection of micrometastases when given intraperitoneally.

To test HAL-induced fluorescence in vivo, we utilised the NuTu19 epithelial ovarian cancer animal model. This model closely simulates clinical human ovarian cancer in terms of (a) method of intraperitoneal spread, (b) formation of malignant ascites, and (c) propensity for local metastases and organ invasion (omentum, peritoneum, liver, spleen, bowel). Our previous experiments with ALA tested time intervals between 0.5 and $4 \mathrm{~h}$ at concentrations between 4 and $20 \mathrm{~mm}$, and showed best discrimination between healthy and cancerous tissue when $8 \mathrm{~mm}$ ALA was applied for $2 \mathrm{~h}$ (Major et al, 1997, 2002a,b). We therefore compared ALA with $\mathrm{HAL}$ at this dosage and time interval. At $8 \mathrm{~mm}$, intraperitoneal application of HAL results in twice as much PpIX formation than the same amount of ALA. These data confirm earlier reports of 
better fluorescence yield of HAL when compared to ALA in vitro (Marti et al, 1999) and in vivo (Lange et al, 1999), and may permit, in clinical use, shorter drug application time while retaining tumour selectivity.

In our model, both HAL and its parent molecule effectively detected small cancerous lesions. Half of these small tumours would have been missed by normal inspection of the abdominal cavity. We have demonstrated that HAL-induced fluorescence is a convenient tool that improves the contrast of fluorescing metastases against healthy tissue and allows the detection of cancer lesions that would not have been discovered by normal inspection. However, from our experiments, we cannot exclude that the conditions of the experimental model used may not have been optimal for HAL, and that varying experimental conditions, such as incubation time with HAL or its delivery vehicle, might further improve the selectivity of fluorescence localisation.

Photodiagnostic techniques such as HAL detection of occult ovarian cancer tumours provide a platform technology that permits minimally intrusive investigation, and could allow

\section{REFERENCES}

Bagley Jr CM, Young RC, Schein PS, Chabner BA, DeVita VT (1973) Ovarian carcinoma metastatic to the diaphragm-frequently undiagnosed at laparotomy. A preliminary report. Am J Obstet Gynecol 116: $397-400$

Buchsbaum HJ, Brady MF, Delgado G, Miller A, Hoskins WJ, Manetta A, Sutton G (1989) Surgical staging of carcinoma of the ovaries. Surg Gynecol Obstet 169: 226-232

Gahlen J, Pietschmann M, Prosst RL, Herfarth C (2001) Systemic vs local administration of delta-aminolevulinic acid for laparoscopic fluorescence diagnosis of malignant intra-abdominal tumors. Experimental study. Surg Endosc 15: 196-199

Gahlen J, Prosst RL, Pietschmann M, Haase T, Rheinwald M, Skopp G, Stern J, Herfarth C (2002) Laparoscopic fluorescence diagnosis for intraabdominal fluorescence targeting of peritoneal carcinosis experimental studies. Ann Surg 235: 252-260

Helewa ME, Krepart GV, Lotocki R (1986) Staging laparotomy in early epithelial ovarian carcinoma. Am J Obstet Gynecol 154: 282-286

Heyerdahl H, Wang I, Liu DL, Berg R, Andersson-Engels S, Peng Q, Moan J, Svanberg S, Svanberg K (1997) Pharmacokinetic studies on 5-aminolevulinic acid-induced protoporphyrin IX accumulation in tumours and normal tissues. Cancer Lett 112: 225-231

Hornung R, Major AL, McHale M, Liaw LH, Sabiniano LA, Tromberg BJ, Berns MW, Tadir Y (1998) In vivo detection of metastatic ovarian cancer by means of 5-aminolevulinic acid-induced fluorescence in a rat model. $J$ Am Assoc Gynecol Laparosc 5: 141-148

Jichlinski P, Forrer M, Mizeret J, Glanzmann T, Braichotte D, Wagnieres G, Zimmer G, Guillou L, Schmidlin F, Graber P, van den Bergh H, Leisinger HJ (1997a) Clinical evaluation of a method for detecting superficial surgical transitional cell carcinoma of the bladder by lightinduced fluorescence of protoporphyrin IX following the topical application of 5-aminolevulinic acid: preliminary results. Lasers Surg Med 20: $402-408$

Jichlinski P, Wagnieres G, Forrer M, Mizeret J, Guillou L, Oswald M, Schmidlin F, Graber P, van den BH, Leisinger HJ (1997b) Clinical assessment of fluorescence cytoscopy during transurethral bladder resection in superficial bladder cancer. Urol Res 25(Suppl 1): S3-S6

Kloek J, Akkermans W, Beijersbergen van Henegouwen GM (1998) Derivatives of 5-aminolevulinic acid for photodynamic therapy: enzymatic conversion into protoporphyrin. Photochem Photobiol 67: 150-154

Kriegmair M, Zaak D, Knuechel R, Baumgartner R, Hofstetter A (1999) Photodynamic cystoscopy for detection of bladder tumors. Semin Laparosc Surg 6: $100-103$

Lange N, Jichlinski P, Zellweger M, Forrer M, Marti A, Guillou L, Kucera P, Wagnieres G, van den Bergh H (1999) Photodetection of early human bladder cancer based on the fluorescence of 5 -aminolaevulinic acid hexylester-induced protoporphyrin IX: a pilot study. $B r$ J Cancer 80: $185-193$ detection by endoscopy and eventually elimination of ovarian cancer cells at their earliest stages. Moreover, detection, diagnosis, and treatment could be closely coupled, enabling effective administration in a single, seamless process. To start with, laparoscopic staging of early ovarian cancer would benefit from this simple and straightforward method of photodetection. Hexaminolaevulinate has greater potency to induce fluorescence in cancerous lesions, and with the acquisition of further data on safety in human, it may replace ALA in topical applications.

\section{ACKNOWLEDGEMENTS}

This work was supported in part by a grant from Roche Research Foundation Basel, Switzerland, Swiss National Science Foundation Bern, Switzerland, Fonds de péréquation Geneva, Switzerland, Leenaards Foundation Lausanne, Switzerland, and Karl Storz GMBH \& CO KG Tuttlingen, Germany.
Lange N, Vaucher L, Marti A, Etter AL, Gerber P, van den Bergh H, Jichlinski P, Kucera P (2001) Routine experimental system for defining conditions used in photodynamic therapy and fluorescence photodetection of (non-) neoplastic epithelia. J Biomed Opt 6: 151-159

Leblanc E, Querleu D, Narducci F, Chauvet MP, Chevalier A, Lesoin A, Vennin P, Taieb S (2000) Surgical staging of early invasive epithelial ovarian tumors. Semin Surg Oncol 19: 36-41

Major AL, Ludicke F, Campana A (2002a) Feasibility study to detect ovarian cancer micrometastases by fluorescence photodetection. Lasers Med Sci 17: 2-5

Major AL, Rose GS, Chapman CF, Hiserodt JC, Tromberg BJ, Krasieva TB, Tadir Y, Haller U, Di Saia PJ, Berns MW (1997) In vivo fluorescence detection of ovarian cancer in the NuTu-19 epithelial ovarian cancer animal model using 5-aminolevulinic acid (ALA). Gynecol Oncol 66: $122-132$

Major AL, Rose GS, Svaasand LO, Ludicke F, Campana A, van Gemert MJ (2002b) Intraperitoneal photodynamic therapy in the Fischer 344 rat using 5-aminolevulinic acid and violet laser light: a toxicity study. $J$ Photochem Photobiol B 66: 107-114

Marti A, Lange N, van den BH, Sedmera D, Jichlinski P, Kucera P (1999) Optimisation of the formation and distribution of protoporphyrin IX in the urothelium: an in vitro approach. J Urol 162: 546-552

Monnier Ph, Savary M, Fontolliet C, Wagnières G, Châtelain A, Cornaz P, Depeursinge Ch, van den Bergh H (1990) Photodetection and photodynamic therapy of 'early' squamous cell carcinomas of the pharynx, oesophagus and tracheo-bronchial tree. Lasers Med Sci 5: $149-169$

Orenstein A, Kostenich G, Malik Z (1997) The kinetics of protoporphyrin fluorescence during ALA-PDT in human malignant skin tumors. Cancer Lett 120: $229-234$

Peng Q, Warloe T, Berg K, Moan J, Kongshaug M, Giercksky KE, Nesland JM (1997) 5-Aminolevulinic acid-based photodynamic therapy. Clinical research and future challenges. Cancer 79: 2282-2308

Piver MS (1982) Optimal surgical therapy in stage I and II ovarian malignancies. Int J Radiat Oncol Biol Phys 8: 247-249

Rose GS, Tocco LM, Granger GA, DiSaia PJ, Hamilton TC, Santin AD, Hiserodt JC (1996) Development and characterization of a clinically useful animal model of epithelial ovarian cancer in the Fischer 344 rat. Am J Obstet Gynecol 175: $593-599$

Soper JT, Johnson P, Johnson V, Berchuck A, Clarke-Pearson DL (1992) Comprehensive restaging laparotomy in women with apparent early ovarian carcinoma. Obstet Gynecol 80: 949-953

Trimbos JB, Schueler JA, van der BM, Hermans J, van Lent M, Heintz AP, Fleuren GJ (1991) Watch and wait after careful surgical treatment and staging in well- differentiated early ovarian cancer. Cancer 67: 597-602

Wagnieres GA, Star WM, Wilson BC (1998) In vivo fluorescence spectroscopy and imaging for oncological applications. Photochem Photobiol 68: $603-632$ 
Webber J, Kessel D, Fromm D (1997) Plasma levels of protoporphyrin IX in humans after oral administration of 5-aminolevulinic acid. J Photochem Photobiol B 37: $151-153$

Workman P, Twentyman P, Balkwill F, Balmain A, Chaplin D, Double J, Embleton J, Newell D, Raymond R, Stables J, Stephens T, Wallace J (1998) United Kingdom Co-ordinating Committee on Cancer Research (UKCCCR) Guidelines for the welfare of animals in experimental neoplasia (second edition). $\mathrm{Br} \mathrm{J}$ Cancer 77: $1-10$

Young RC, Decker DG, Wharton JT, Piver MS, Sindelar WF, Edwards BK, Smith JP (1983) Staging laparotomy in early ovarian cancer. JAMA 250: $3072-3076$ 